\title{
Effect of the Densification of the Reinforced-Asphalt Mixtures on the Permanent Deformation
}

\author{
Adham Alnadish*1 and Mohamad Yusri Aman ${ }^{1}$ \\ ${ }^{1}$ Department of Civil and Environmental Engineering, Universiti Tun Hussein Onn Malaysia- 86400 Parit Raja, Malaysia. \\ adhmalnadish@gmail.com
}

\begin{abstract}
This study aimed to provide a novel contribution in terms of introducing a better understanding for evaluating the resistance of the reinforced asphalt mixtures to permanent deformation. The resistance of asphalt mixtures to permanent deformation was assessed using dynamic creep test at a temperature of $40{ }^{\circ} \mathrm{C}$. Four mixtures named Mix1, Mix2, Mix3, and Mix 4 were evaluated, Mix 1 corresponds to the control mixture that containing coarse steel slag aggregate while Mix2, Mix3, and Mix4 represent the reinforced mixtures with polyester fiber at the proportions of $0.05,0.15$, and $0.3 \%$, respectively. The findings of this study showed that the elastic deformation occurred at the primary stage has a negative influence regarding the permanent deformation assessment. In addition, increasing the content of the polyester fiber has a positive relationship with the elastic stage; the higher the proportion of the fiber, the higher the deformation at the elastic stage, which have a negative effect on the evaluation of the mixtures resistance to permanent deformation, if the deformation occurred at the elastic stage is not neglected. On the other hand, the mixtures containing a high content of polyester fiber exhibited better resistance to the permanent deformation at the viscoelastic stage.
\end{abstract}

Keywords. Polyester fiber; steel slag; permanent deformation; densification; elastic stage; viscoelastic stage

\section{Introduction}

Asphalt mixtures consist of coarse and fine aggregate and bitumen (binder) [1]. However, the binder acts like a glue to the mixture that holds the aggregate in order to produce mixtures with stable and durable properties to resist the traffic loads. In some cases, the binder does not perform well due to the elevated temperature as well as the increase in the traffic volume. Thus, it is necessary to modify the binder with certain additives in order to enhance its physical properties [2, 3]. In this regard, the polymers and copolymers are common additives used to improve the physical properties of the binder; in addition, it is proven that these additives enhance the mechanical properties of the mixtures regarding the resilient modulus, the resistance of the mixtures to permanent deformation and cracking [4-6].

However, the main disadvantage which is considered as a main concern in modifying of the binder with polymers and copolymers additive, that it produces a binder with poor storage stability; in addition, modifying the binder with these additives requires high mixing temperature and long period for mixing to produce a uniform modified binder; hence, toxic emissions and energy consumption. Furthermore, it is proven that these additives accelerate aging of the layer in the field; thus, the service life of asphalt layer is decreased; this is because when the

\footnotetext{
${ }^{1}$ Corresponding author: adhmalnadish@gmail.com
} 
asphalt layer is aged it becomes too stiff; hence, it is susceptible to rutting accompanying with longitudinal cracking, which required in some cases full-depth rehabilitation [7-14].

\section{Reinforcing of the asphalt mixtures with fibers}

Due to the sensitivity of the binder, the researchers tend to modify the asphalt mixtures in order to reduce the factors that may affect the performance of asphalt mixtures as well as to produce mixtures with superior performance. However, fibers are well-known materials used to reinforce the mixtures for many decades due to its great abilities to enhance the resistance of the asphalt layer to cracking, rutting and moisture sensitivity. Natural fibers, i.e. coconut, cellulose, sisal, wool, vegetable, cotton, flax, and asbestos are types of the natural fibers used in the asphalt mixtures to improve the performance of the asphalt mixture concerning of resilient modulus, permanent deformation and cracking. Additionally, due to the high absorption rate of the natural fibers; thus, the natural fibers are desirable in modifying stone mastic asphalt (SMA) because it prevents the drainage of the binder during the production and placing of the mixtures because it absorbs the bitumen [15-17]. In similar content, synthetic fibers, i.e. polypropylene, polyester, polyvinyl alcohol, polyacrylonitrile, aramid, basalt, glass, and steel are used to produce reinforced dense-graded asphalt mixtures in order to improve the performances of asphalt mixtures. It is proven that the reinforced asphalt mixtures with synthetic fibers have superior properties with regard to stiffens modulus, the resistance of the mixtures to rutting, cracking, and moisture susceptibility that represents the main damages in the asphalt layer [18-22].

In addition, reinforced dense-graded asphalt mixtures with synthetic fiber may increase the initial cost of the mixtures, but it increases the service life of asphalt layer and decrease the thickness of asphalt layer; thus, saving cost of the maintenance as well as costs of the transportation and reducing the demand for the natural aggregate [23, 24]. The cost of the synthetic fiber depends on the optimum dosage; hence, introducing of the lightweight fibers into mixtures may provide mixtures with low cost comparing to the reinforced mixtures with fibers that have high density; in other words, introducing fiber with high density at the optimum content may equal double of the optimum content of lightweight fibers.

\section{The relationship between the densification and the permanent deformation}

Permanent deformation (rutting) is one of the significant distresses that affect the service life of asphalt layer, in some cases, it requires full-depth rehabilitation for the asphalt layer due to the significant rut depth. However, rutting depth may occur due to the densification of the mixtures (change in volume) and improper compaction as well as excessive in the air voids content, the level of this rut depth is considered as low. Similarly, the moderately level of rutting depth caused by the lateral flow, which is generated by the applied load by the wheel on the surface layer. Additionally, the significant/high level of rutting depth occurred by the lateral movement due to the subsistence in the subgrade layer, this rutting might be accompanied by a longitudinal cracking, if the asphalt layer become too stiff; however, this rutting may occur at the top of $100 \mathrm{~mm} \mathrm{[25,26].}$

Furthermore, there is a lack of information in terms of illustrating the effect of the densification of the reinforced mixtures on the permanent deformation. As known, adding fibers into mixtures may increase the height of the sample because that some fibers are lightweight; however, this is can be observed on the specific gravity of the reinforced mixtures. The specific gravity (density) of the reinforced mixtures shows slight decreasing in the density compared to the unreinforced mixtures [27, 28]. This is attributed to the slight increment in the height of the compacted sample, in which the specific gravity of the compacted sample depends on the weight of the water displaced by the sample and the sample dimensions (volume). In other words, introducing fiber at the high content increases the volume of the sample (height of the sample) whereas the change in the weight of the sample still small compared to the change in the volume; thus, the weight of the sample in water is decreased. However, the higher the content of the lightweight fiber, the lower the specific gravity. Due to the fact that, the densification is occurred because of the decreasing in the thickness of the sample/layer after applying the load/traffic densification; hence, the density of the sample/layer is increased. Consequently, the reinforced mixtures with the lightweight fibers are highly affected by the densification. 


\section{Steel slag aggregate}

Steel slag is considered as a waste material because it is a by-product of steelmaking. However, utilizing steel slag aggregate in the civil applications is viewed as sustainable practice because it depreciates the need for the raw material concerning of the natural aggregate. However, one of the disadvantages of using steel slag aggregate is the high density of the steel slag aggregate that may increase the transportation costs. Furthermore, it is proven that replacing the natural aggregate with the coarse steel slag aggregate improves the mechanical properties of the mixtures in terms of resilient modulus, permanent deformation, and cracking resistance. In addition, introducing the synthetic fiber may reduce the thickness of the asphalt layer because the enhancements on the performance of the mixtures; thus, the transportation cost may minimize [20].

Lastly, the objective of this study is to evaluate the performance of the asphalt mixture incorporating coarse steel slag aggregate and reinforced with polyester fiber in terms of permanent deformation. In addition, to correlate the change in density with the elastic behavior in order to provide a better evaluation and understanding of the reinforced asphalt mixtures, when it is subjected to the compressive strength.

\section{Materials and Methods}

\subsection{Materials}

The grade of the bitumen used is $80 / 100$, which is equivalent to PG 64, produced by PETRONAS Malaysia. The natural coarse aggregate (granite) were replaced with coarse Electric arc furnace (EAF) steel slag; however, steel slag aggregate was supplied by NSL, Singapore, while the granite aggregate provided by Hanson quarry, Johor, Malaysia. Additionally, the polyester fiber used in this study was supplied from Mainland, China. Fig.1 and Table1 display the polyester fiber shape and the physical properties of the fiber (provided by the supplier), respectively. Denes-graded with nominal maximum size aggregate of $12.5 \mathrm{~mm}$ was adopted, the finer gradation was selected in order to reduce/eliminate the effect of the porosity of steel slag aggregate on bitumen content, and Fig.2 shows the selected gradation.

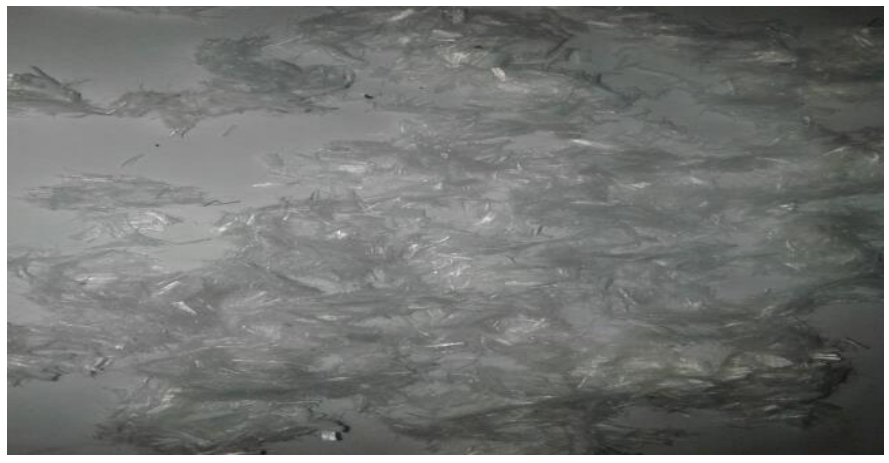

Fig.1. Polyester fibers 
Table1. Polyester fiber physical properties

\begin{tabular}{|c|c|}
\hline Material Property & Measure \\
\hline Material & polyester \\
\hline Density & $1.36(\mathrm{~g} / \mathrm{cm} 3)$ \\
\hline Tensile Strength & $>500 \mathrm{Mpa}$ \\
\hline Young Modulus & $>7 \mathrm{Gpa}$ \\
\hline Melting Point & $>240{ }^{\circ} \mathrm{C}$ \\
\hline Color & white \\
\hline Length & $6 \mathrm{~mm}$ \\
\hline Diameter & $10-25 \mathrm{um}$ \\
\hline
\end{tabular}

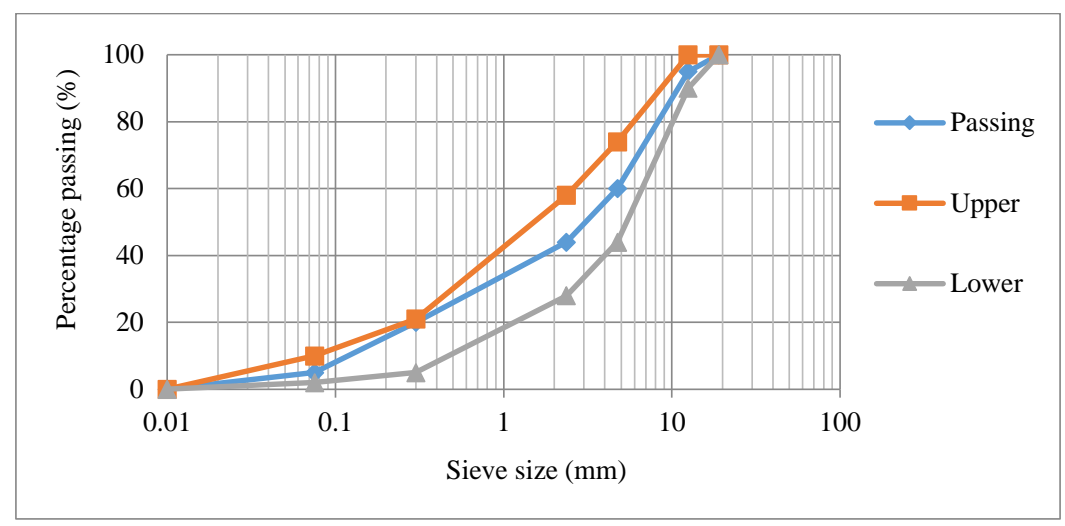

Fig.2. Gradation of designed aggregate

\subsection{Samples preparation}

In this study, polyester fibers were introduced to the asphalt mixture incorporating coarse steel slag aggregate at different proportions; i.e. $0.05,0.15$ and $0.3 \%$ by the total weight of the aggregate. The mixtures that were prepared named Mix 1 , Mix2, Mix3, and Mix4. Mix1 represents the control mixture while Mix2, Mix3, and Mix4 correspond to the reinforced asphalt mixtures with polyester fiber at the dosages of $0.05,0.15$ and $0.3 \%$, respectively. The mixtures were prepared based on the specification of Superpave. The dried aggregate were heated at mixing temperature of $160{ }^{\circ} \mathrm{C}$ for four hours; the mixing and compaction temperatures were determined based on the viscosity of the bitumen to ensure that the bitumen is able to coat the aggregate. Thereafter, the heated bitumen and aggregate, as well as polyester fiber, were mixed for three minutes in the automatic mixer. The prepared mixtures were kept in an oven at the compaction temperature of $150{ }^{\circ} \mathrm{C}$ to simulate the short-term aging. The Superpave Gyratory Compactor with 100 revolutions were adopted to produce the compacted samples.

Prior testing, the volumetric properties of the compacted specimens were determined in order to meet the requirements of Superpave. The content of the air voids of Mix1, Mix2, and Mix 3 were 4, 4, and 4.35\%; respectively, at the optimum bitumen content of $4.9 \%$. The content of air voids and optimum bitumen content for Mix 4 were 4.3 and $5.2 \%$. In addition, adding polyester fiber have decreased the specific gravity (density) by around $0.25,0.64$, and $0.76 \%$ for Mix2, Mix3, and Mix4 compared to Mix1. This is attributed to the slight increment in the thickness of the compacted sample, which decreased the weight of the compacted samples in the water. 


\subsection{Dynamic creep test}

The permanent deformation of the mixtures is measured using the dynamic creep test; however, the deformation that occurred depends on the applied compressive strength as well as the type of the wave pulses loading. Furthermore, the pulse wave of haversine and square pulses are the common types used in the dynamic creep test, due to its abilities to simulate the pulses loads of the vehicles on the pavement layer. In addition to that, the width and rest period of the pulse loading is the most important parameter, which directly affects the deformation; in other words, increasing the pulse loading width/reducing the rest period is offset by an increase in the deformation. However, there are no limitations for this test to be as a criterion for evaluating asphalt mixtures. The main use of the dynamic creep test is to create a comparison among various types of asphalt mixtures.

In this study, dynamic creep was performed in accordance with British standard BS DD 226. Prior testing, the samples of the test were kept in an oven at a temperature of $40{ }^{\circ} \mathrm{C}$ for four hours to ensure distribution temperature within the samples. However, the selected temperature is suitable to evaluate the permanent deformation because at this temperature the bitumen becomes soft; hence, the aggregate may lose the bonding with bitumen; thus, the mixtures are susceptible to the deformation when it is subjected to compressive strength. However, a servo-hydraulic machine called UTM-5P was used to evaluate the permanent deformation. A stress of $12 \mathrm{kPa}$ was applied on the specimens for two minutes as preload to ensure the contacting between the load and the sample. Thereafter, the samples were subjected to a repetitive compressive strength of $200 \mathrm{kPa}$ for 3600 seconds; the compressive strength was applied with a wave pulse of square, the pulse load consists of 1-second width and 1-second rest period, the total of cycles were 1800 . The deformation of the sample was measured using LVDTs.

\section{Results and discussions}

\subsection{Permanent deformation of the reinforced mixtures}

The ultimate permanent deformation of the reinforced mixtures occurred after 1800 cycles is shown in Fig.3. As shown in the figure the asphalt mixtures incorporation $0.05 \%$ of polyester fiber have reduced the permanent deformation by approximately $11 \%$ compared to Mix 1 . While adding of polyester fiber at the proportions of $0.15 \%$ (Mix 3 ) by total weight of the aggregate exhibited slightly lower permanent deformation than the control mixture by $4 \%$. This is attributed to the fact that permanent deformation is highly affected by the aggregate matrix (interlocking) and the viscous of the bitumen; in other words, the higher the viscosity of the bitumen the higher the softening point. Thus, introducing the fiber at the proportions of 0.05 and $0.15 \%$ have increased the bitumen softening point due to the slight absorption by the fiber as well as coating fibers with binder may enhance the hardness of the bitumen at the elevated temperature. Furthermore, Mix4 showed the highest permanent deformation compared to the other mixtures. This is because increasing the fiber dosage have increased the height of the sample; thus, the sample is highly affected by the densification occurred at the primary stage, which is corresponds to the elastic deformation.

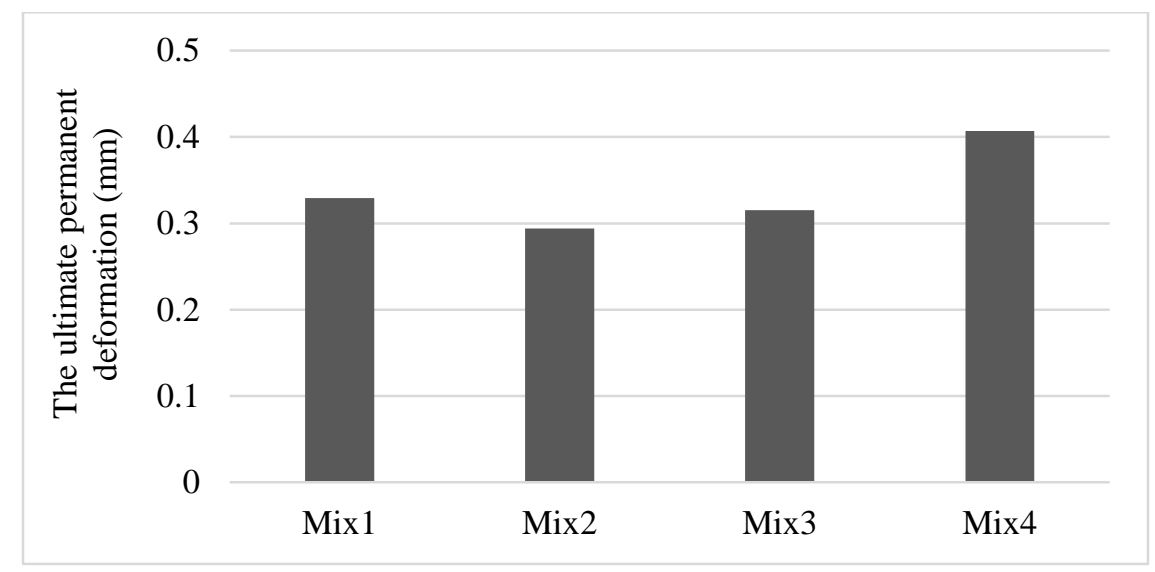

Fig.3. The ultimate permanent deformation of the reinforced mixtures 
As known, the permanent deformation consists of three stages; the primary stage represents the recoverable elastic deformation that caused by the densification due to the change in volume or improper compaction. While the second stage corresponds to the irrecoverable viscoelastic strain that occurred due to the actual deformation after exceeding the elasticity stage; however, the third stage represents the failure of the sample [28-30].

However, since the elastic deformation is recoverable; hence, when the applied load is removed, the deformation may recovery and the sample may back to its original state. He et al. [29] suggested that the deformation that occurs at the primary stage must be neglected in the evaluation, because the deformation at the primary stage is recoverable, which occurred by the densification and not by the actual strain. In addition, the deformation occurs at the viscoelastic stage is the critical damage because the deformation at the secondary stage is irrecoverable. Furthermore, He et al. [29] proposed that the primary stage occurs at the first third of the number of cycles; consequently, the deformation occurred at the $1 / 3$ of the number of cycles should be neglected in the evaluation.

The number of the cycles in this study were 1800 cycles, and the number of cycles to overcome the primary stage (elastic deformation) are 600 cycles; thus, the deformation occurred at the first 600 cycles is neglected in order to evaluate the permanent deformation at the viscoelastic stage, through neglecting the deformation caused by the densification. Fig. 4 presents the permanent deformation of the reinforced mixtures at the viscoelastic stage that excluded the deformation at the primary stage. As concluded from the figure, Mix2, Mix3, and Mix4 have reduced the permanent deformation in comparison with Mix 1 by approximately 14,9 , and $4 \%$, respectively. It can be said, that the densification of the reinforced mixtures have negative influences in the evaluation for the resistance of the mixtures to the permanent deformation, if it is not neglected in the assessment while the resistance of the reinforced mixtures to the permanent deformation at the viscoelastic stage have improved.

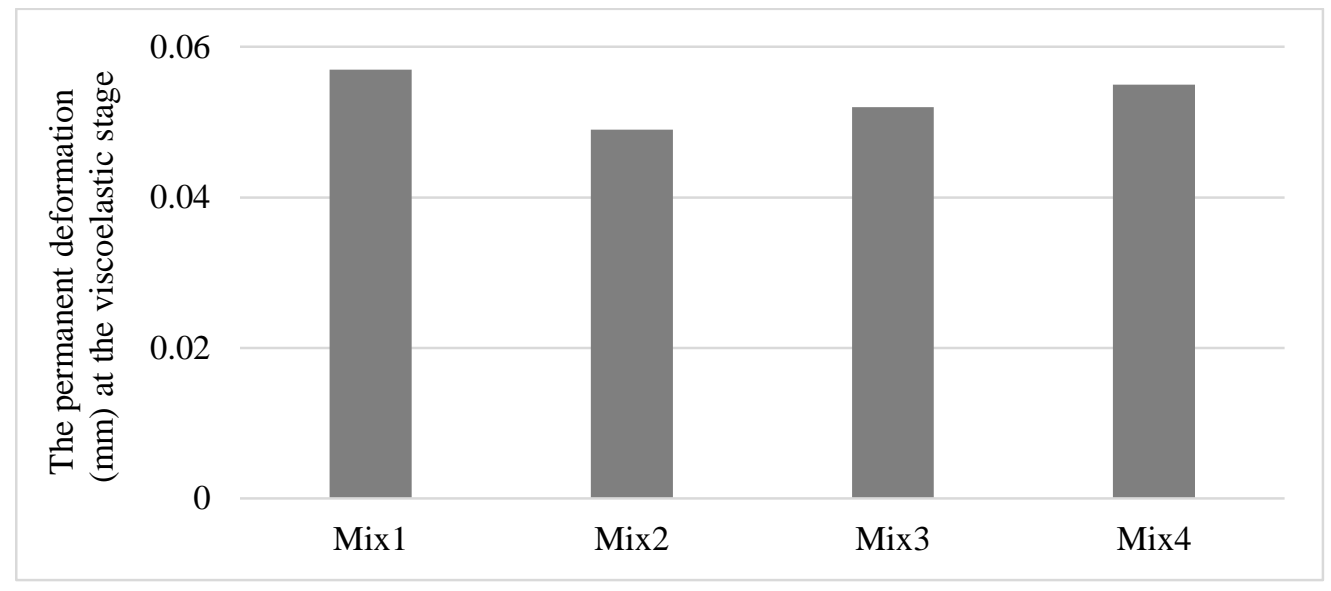

Fig.4. The permanent deformation of the reinforced mixtures at the viscoelastic stage

\subsection{Estimation of the rut depth}

Van de Loo [31] developed a method to estimate the rut depth in the asphalt layer. The estimated rut depth is determined based on the permanent deformation that occurred by the lateral flow/plastic movement, which is generated by the traffic loads at the elevated temperature. In addition, the estimated rut depth excludes the permanent deformation caused by the subsistence of subgrade layer. The rutting depth is calculated form Eq.1:

$$
\text { Rut depth }(\mathrm{mm})=C_{m} h_{1} \quad\left(\frac{\sigma_{a v}}{s_{m i x}}\right)
$$

Where $C_{m}$ is a correction factor with a value ranging from 1-2 depending on the mixtures types. Finn et al. [32] suggested that $C_{m}$ should be 1 if the resilient modulus of the mixture was obtained from the dynamic creep test outputs at the viscoelastic stage. However, the number of the load applications in-place equal to the number of the load cycles for dynamic creep test multiplied by 10. In addition, $h_{1}$ represents the thickness of asphalt layer while $\sigma_{a v}$ corresponds to 
the average vertical stress on the asphalt layer, and $s_{m i x}$ is the resilient modulus of mixtures that obtained from dynamic creep test.

In order to determine the rut depth; the thickness of asphalt layer was assumed as $100 \mathrm{~mm}$ and a load of the standard dual wheel was adopted as the vertical stress (compressive strength) with a stress of $577 \mathrm{kPa}$ and a radius of $105 \mathrm{~mm}$; however, the $\sigma_{a v}$ is calculated as $577 / 2=288.5 \mathrm{kPa}$. Fig.5 illustrates the resilient modulus of the mixtures, which obtained from the dynamic creep test outputs at the viscoelastic stage as well as the estimated rutting depth. As clearly shown in Fig.5 the estimated rut depth after 18000 of load applications for Mix1, Mix2, Mix3, and Mix4 were 0.069, $0.0645,0.0661$, and $0.0674 \mathrm{~mm}$, respectively. Mix 2 exhibited the lowest rut depth compared to all mixtures, which indicates that adding the fiber have enhanced the resistance of the mixture to permanent deformation. In addition, Mix 3 and Mix 4 showed lower rut depth than Mix 1 by 4.2 and 2.4\%.

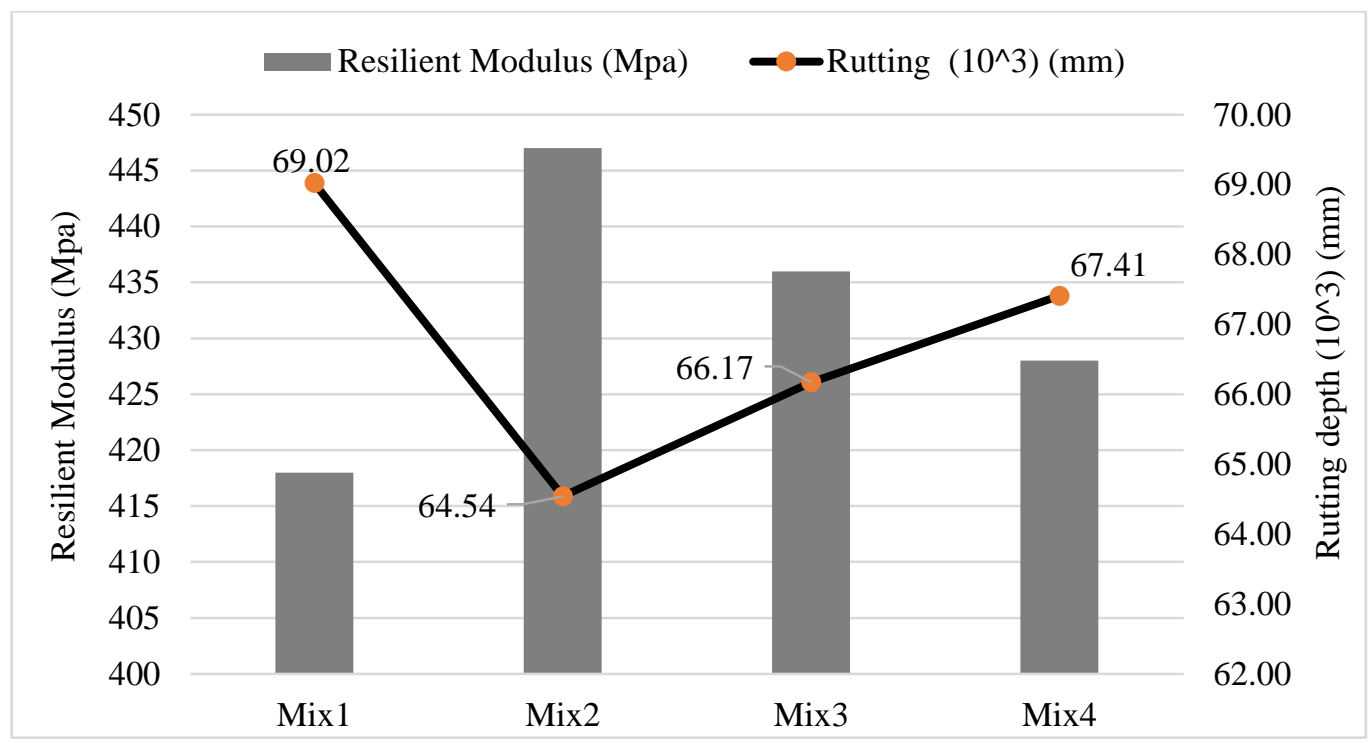

Fig.5. The estimated rut depth of the reinforced mixtures

\section{Conclusions}

Based on the results and discussions, the following conclusions were made:

- Introducing polyester fibers to the mixtures have greatly enhanced the elasticity behavior of the asphalt mixtures.

- Adopting the ultimate deformation as the main parameter to evaluate the resistance of asphalt mixtures to permanent deformation without taking in account the deformation occurred in the elastic stage may an inaccurate assessment, in particular for the mixtures that have a high elasticity behavior.

- Regarding the optimum fiber content, the outputs of the dynamic creep test at the viscoelastic stage (non-recoverable deformation) showed that there is an improvement in terms of the resistance of the mixtures incorporating high content of fibers to the permanent deformation compared to the unreinforced mixture. Thus, adding polyester fiber at the content of $0.3 \%$ by total weight of the aggregate represents the optimum content due to its ability to improve the flexibility of the asphalt layer. Therefore, it offers rapid recovery for the deformation as well as it may enhance the service life of asphalt layer because it requires higher traffic densification than the unreinforced mixtures to fall to the final air voids (4-3\%) during the service life of asphalt layer.

- Increasing effort of the compaction in the field in order to control the change in volume of the reinforced mixtures may densify the mixtures; thence, the content of the air voids in the mixture may decrease because the optimum bitumen content produces samples with air voids content of approximately $4 \%$. Thereafter, the asphalt mixtures become unstable and highly susceptible to permanent deformation. However, increasing the effort of the compaction 
depends on the amount of the change in volume. In other words, the slight change in volume is desirable because it increases the initial service life of asphalt layer.

\section{Acknowledgment}

The authors would like to thank Office for Research Management Centre (RMC) in Universiti Tun Hussein Onn Malaysia (UTHM) for financial support through the university research grant vote (U570).

\section{REFERENCES}

[1] "The Shell Bitumen Handbook, 5th edition," 2003.

[2] M. S. Cortizo, D. O. Larsen, H. Bianchetto, and J. L. Alessandrini, "Effect of the thermal degradation of SBS copolymers during the ageing of modified asphalts," Polymer Degradation and Stability, vol. 86, no. 2, pp. 275282, Nov. 2004.

[3] Y. Yildirim, "Polymer modified asphalt binders," Construction and Building Materials, vol. 21, no. 1, pp. 66-72, Jan. 2007.

[4] G. Polacco, A. Muscente, D. Biondi, and S. Santini, "Effect of composition on the properties of SEBS modified asphalts," European Polymer Journal, vol. 42, no. 5, pp. 1113-1121, May 2006.

[5] M. R. Mitchell, R. E. Link, S. Ghaffarpour Jahromi, B. Andalibizade, and A. Khodaii, "Mechanical Behavior of Nanoclay Modified Asphalt Mixtures,"Journal of Testing and Evaluation, vol. 38, no. 5, p. 102196, 2010.

[6] T. F. Pamplona, B. de C. Amoni, A. E. V. de Alencar, A. P. D. Lima, N. M. P. S. Ricardo, J. B. Soares, and S. de A. Soares, "Asphalt binders modified by SBS and SBS/nanoclays: effect on rheological properties," Journal of the Brazilian Chemical Society, 2012.

[7] C. Ouyang, S. Wang, Y. Zhang, and Y. Zhang, "Low-density polyethylene/silica compound modified asphalts with high-temperature storage stability," Journal of Applied Polymer Science, vol. 101, no. 1, pp. 472-479, 2006.

[8] M. S. Cortizo, D. O. Larsen, H. Bianchetto, and J. L. Alessandrini, "Effect of the thermal degradation of SBS copolymers during the ageing of modified asphalts," Polymer Degradation and Stability, vol. 86, no. 2, pp. 275282, Nov. 2004.

[9] M. Ragab and M. Abdelrahman, "Enhancing the crumb rubber modified asphalt's storage stability through the control of its internal network structure," International Journal of Pavement Research and Technology, vol. 11, no. 1, pp. 13-27, Jan. 2018.

[10] M. Sienkiewicz, K. Borzędowska-Labuda, A. Wojtkiewicz, and H. Janik, "Development of methods improving storage stability of bitumen modified with ground tire rubber: A review," Fuel Processing Technology, vol. 159, pp. 272-279, May 2017.

[11] D. K. Paul, O. Sirin, and E. Kassem, "Laboratory investigation of asphalt mixture aging," Proceedings of 6th Eurasphalt \& Eurobitume Congress, Jun. 2016.

[12] A. Pérez-Lepe, F. J. Martínez-Boza, and C. Gallegos, "High temperature stability of different polymer-modified bitumens: A rheological evaluation," Journal of Applied Polymer Science, vol. 103, no. 2, pp. 1166-1174, 2006.

[13] S. Kim, S. H. Lee, O. Kwon, J. Y. Han, Y. S. Kim, and K. W. Kim, "Estimation of service-life reduction of asphalt pavement due to short-term ageing measured by GPC from asphalt mixture," Road Materials and Pavement Design, vol. 17, no. 1, pp. 153-167, Aug. 2015.

[14] S. Wu, Z. Zhao, Y. Li, L. Pang, S. Amirkhanian, and M. Riara, "Evaluation of Aging Resistance of Graphene Oxide Modified Asphalt," Applied Sciences, vol. 7, no. 7, p. 702, Jul. 2017.

[15] M. Panda, A. Suchismita, and J. Giri, "Utilization of Ripe Coconut Fiber in Stone Matrix Asphalt Mixes," International Journal of Transportation Science and Technology, vol. 2, no. 4, pp. 289-302, Dec. 2013.

[16] A. C. do Vale, M. D. T. Casagrande, and J. B. Soares, "Behavior of Natural Fiber in Stone Matrix Asphalt Mixtures Using Two Design Methods," Journal of Materials in Civil Engineering, vol. 26, no. 3, pp. 457-465, Mar. 2014.

[17] O. S. Abiola, W. K. Kupolati, E. R. Sadiku, and J. M. Ndambuki, "Utilisation of natural fibre as modifier in bituminous mixes: A review," Construction and Building Materials, vol. 54, pp. 305-312, Mar. 2014.

[18] P. Park, S. El-Tawil, S.-Y. Park, and A. E. Naaman, "Cracking resistance of fiber reinforced asphalt concrete at $-20^{\circ} \mathrm{C}$," Construction and Building Materials, vol. 81, pp. 47-57, Apr. 2015.

[19] Z. Chen, S. Wu, Z. Zhu, and J. Liu, "Experimental evaluation on high temperature rheological properties of various fiber modified asphalt binders," Journal of Central South University of Technology, vol. 15, no. S1, pp. 135-139, Sep. 2008.

[20] A. M. Alnadish and Y. M. Aman, "Mechanistic Approach for Reducing the Thickness of Asphalt Layer Incorporating Steel Slag Aggregate," Civil Engineering Journal, vol. 4, no. 2, p. 334, Mar. 2018.

[21] A. Alnadish and Y. Aman, "Evaluation of Aramid Fibre-Reinforced Asphalt Mixtures," Lecture Notes in Civil Engineering, pp. 1377-1388, May 2018. 
[22] H. K. Shanbara, F. Ruddock, and W. Atherton, "A laboratory study of high-performance cold mix asphalt mixtures reinforced with natural and synthetic fibres," Construction and Building Materials, vol. 172, pp. 166-175, May 2018.

[23] A. I. Al-Hadidy and T. Yi-qiu, "Mechanistic approach for polypropylene-modified flexible pavements," Materials \& Design, vol. 30, no. 4, pp. 1133-1140, Apr. 2009.

[24] A. Mokhtari and F. Moghadas Nejad, "Mechanistic approach for fiber and polymer modified SMA mixtures," Construction and Building Materials, vol. 36, pp. 381-390, Nov. 2012.

[25] J. Zhang, E. Ray Brown, P. Kandhal, and R. West, "An Overview of Fundamental and Simulative Performance Tests for Hot Mix Asphalt,” Journal of ASTM International, vol. 2, no. 5, p. 12254, 2005.

[26] H. Chen, Q. Xu, S. Chen, and Z. Zhang, "Evaluation and design of fiber-reinforced asphalt mixtures," Materials \& Design, vol. 30, no. 7, pp. 2595-2603, Aug. 2009.

[27] Q. Xu, H. Chen, and J. A. Prozzi, "Performance of fiber reinforced asphalt concrete under environmental temperature and water effects," Construction and Building Materials, vol. 24, no. 10, pp. 2003-2010, Oct. 2010.

[28] F. Zhou and T. Scullion, "Discussion: Three Stages of Permanent Deformation Curve and Rutting Model," International Journal of Pavement Engineering, vol. 3, no. 4, pp. 251-260, Dec. 2002.

[29] G. He and W. Wong, "Laboratory study on permanent deformation of foamed asphalt mix incorporating reclaimed asphalt pavement materials," Construction and Building Materials, vol. 21, no. 8, pp. 1809-1819, Aug. 2007.

[30] H. Y. Katman, M. R. Ibrahim, M. R. Karim, N. Salim Mashaan, and S. Koting, "Evaluation of Permanent Deformation of Unmodified and Rubber-Reinforced SMA Asphalt Mixtures Using Dynamic Creep Test," Advances in Materials Science and Engineering, vol. 2015, pp. 1-11, 2015.

[31] Van de Loo, P. J. (1978). Creep Test: A Key Tool in Asphalt Mix Design and In the Prediction of Pavement Rutting. In Association of Asphalt Paving Technologists Proc (Vol. 47).

[32] Finn, F. N., Monismith, C. L., \& Markevich, N. J. (1983). Pavement Performance and Asphalt Concrete Mix Design (With Discussion). In Association of Asphalt Paving Technologists Proceedings (Vol. 52). 